\title{
Sex differences and effects of sex of examiner in early conservation ability
}

\author{
JOSEPH D. SCLAFANI and RICHARD C. LaBARBA \\ University of South Florida, Tampa, Florida 33620
}

\begin{abstract}
Twenty-four male and 24 female kindergarten and first-grade students were assessed on two conservation-of-number tasks and a conservation-of-continuous-quantity task to determine whether sex differences exist in conservation ability development and to investigate whether sex of examiner influences conservation performance. No significant sex difference effects were obtained, and the sex of experimenter was not found to reliably influence conservation performance. Support was found for the Piagetian notion of stages in conservation development. A discussion of the reliability of the methodology employed, a compromise between Piaget's clinical method and standardized assessments, is also presented.
\end{abstract}

The conservation problem has been perhaps the foremost topic of research in Piaget's theory of cognitive development. Exhaustive investigations of the roles of such subject variables as age, sex, and intelligence, along with experimenter variables such as expectancy and methodology, have been linked to various conservation abilities (Mogdil \& Mogdil, 1976). In Genevan psychology, the schema of conservation refers to a child's ability to retain, or conserve, the constancy of a stimulus object following a transformation of its physical appearance. Success on a conservation task is taken as evidence of the capacity for logical thought. Conservation ability also serves to delineate a child's transition from the prelogical preoperational period to the logical concrete-operational period (Brainerd, 1978).

Conservation of number and continuous quantity are the first conservation tasks to be mastered by concreteoperational children (Brainerd, 1978; Goldschmid, 1967). According to Piaget, children pass through three global stages in an invariant order from the preoperational (preschoolers) to a transitional stage of inconsistent conservation (6-7 years old), and then on to the third stage of true conservers at the age of approximately 8 years (Brainerd, 1978).

A number of studies have been directed to the question of sex differences in cognitive development and performance. Maccoby and Jacklin (1974) have reported that reliable sex differences in cognitive ability do not appear until 13 or 14 years of age. The absence of sex differences prior to this time has been attributed partly to shared experiences (i.e., school curricula) during elementary school. The general conclusion is that reported sex differences in early cognitive development are secondary, or environmentally induced, differences rather than primary, biologically based, sex differences (Wittig \& Peterson, 1979).

Requests for reprints should be sent to the senior author, Department of Psychology, University of South Florida, Tampa, Florida 33620.
Although sex differences in cognitive development were never directly addressed by Piaget, his theory suggests that there are none (Goldschmid, 1967), and the majority of studies support this conclusion (e.g., Elkind, 1967). However, contradictory results appear sporadically in the literature, even though most reports of sex differences in early cognitive development are presented incidentally. Goldschmid (1967) found that boys performed "at a higher level" than girls on 10 different conservation tasks. These results were attributed to differential opportunity, favoring girls, to manipulate objects and to perceive their transformations. Brekke and Williams (1973) reported that in a group of first-graders, girls conserved more often than boys on four of five tasks, and significantly so on two substance tasks. Brekke and Williams also observed that boys conserved more on tests of conservation of number, although that difference was not reliable.

A major source of criticism directed toward conservation research has been the lack of a standardized assessment procedure. Piaget's insistence on the need for his "method of critical exploration" rests in the belief that flexible testing is essential to reveal the complexities of cognitive development (Brainerd, 1978). One well researched topic in this general area is the effect of experimenter bias, since the subjective nature of Piaget's clinical method allows for a source of variance that experimental procedures control.

Some reports suggest that attributes such as experimenter empathy and perceptiveness may enter into data acquisition, whereas others suggest that examiner expectancy and sex of examiner influence findings of sex differences in conservation performance among children (Brekke \& Williams, 1973; Hunt, 1975). Although compromise procedures that permit free verbal exchanges between examiner and child while employing standardized stimulus presentation rules and scoring criteria represent a methodological improvement (Almy, Chittenden, \& Miller, 1966; Brown, 1973; 
Lloyd, 1971), experimenter bias remains a serious problem in this area of research.

The purpose of the present study was to investigate sex differences in conservation ability in early elementary school children and to determine the extent to which sex of examiner may play a role in children's performance on conservation-of-number and continuousquantity tasks.

\section{METHOD}

Subjects consisted of 24 male and 24 female kindergarten and first-grade students enrolled in a public elementary school, ranging in age from 60 to 87 months. The mean age of the male subjects was 74.5 months, and that for the female subjects was 73.7 months.

The stimuli used were sets of 18 red and 18 black plastic checkers for the conservation-of-number tasks. To assess conservation of continuous quantity, two equal-size $315-\mathrm{ml}$ clear plastic drinking glasses and a shallow bowl $(15.75 \mathrm{~cm})$ were used.

A 2 (sex of subject) by 2 (sex of experimenter) factorial design, with subjects matched by sex, age, and grade and order of tasks balanced across groups, was employed. Experimenters were trained to present the conservation tasks in a standardized manner. In addition, the experimenters were given a review of previous conservation studies and a period of discussion regarding possible outcomes, so that a controlled expectancy set could be established.

The task administration procedure is fully described in Almy et al. (1966). Tasks 1 and 2 assessed conservation of number. Task 1 involved two rows of checkers, one of which was altered after row equivalence was determined by the subject. Task 2 consisted of the presentation of a row of 11 checkers that the subject had to count. Help with counting was provided if needed. Alterations in the row were then made, and the subject was asked about the number. In both tasks, the subjects were allowed two opportunities to explain their responses. In Task 3, conservation of continuous quantity, the subject was first required to demonstrate equivalence between the glasses of colored water. The experimenter than poured the contents of one glass into the bowl and asked the subject whether the contents were equal and why. The entire procedure lasted 5-7 min for each subject. Each session was audio-taped for later scoring.

Two female judges independently rated each response as being a correct or incorrect conservation response and explanation. The raters were taught the differences in conservation stage and were trained using the categorical criterion set of Greenfield (1966).

The trial tapes were edited so that only subject identification numbers, along with questions and responses, were available to the judges. All other extraneous verbal material was erased from the tapes. Judges were unable to determine sex of subject from the tapes.

The scoring procedure used was that first described by Lloyd (1971). Briefly, subjects were scored on their ability to recognize initial equivalency, to correctly respond to transforms, and to adequately explain their responses. Maximum scores on Tasks 1 and 2 were four points each, and the maximum was three points on Task 3.

School teachers were asked to estimate each child's ability in math and language skills by assigning a stanine value for each, along with a performance rating of above, at, or below grade level in these two areas.

\section{RESULTS AND DISCUSSION}

ANOVA performed on the scores for Tasks 1, 2, 1 and 2 , and 3 and total scores revealed a significant examiner sex effect on Task 2 scores $(p<.05)$. No significant main effect of sex of subject or significant interaction effects were found. A series of $t$ tests indicated that order of task presentation did not significantly affect scores. Interrater reliabilities ranged from. $\mathrm{r}=.91$ to $\mathrm{r}=.99$ on task scoring $(\mathrm{p}<.001)$.

Correlations between conservation performance and teacher academic ratings showed no consistent or meaningful pattern. No significant differences were found through t-test comparisons of math and language stanine ratings and sex of subject. Similarly, no differences were found in the comparison of sex of subject and estimated stanines by grade level.

On the number tasks, chi-square analyses revealed a nearly significant $(\mathrm{p}<.055)$ relationship between age and conservation status (Stage 1,2, or 3 ) and a significant relationship between grade and conservation status $(\mathrm{p}<.01)$. The following criteria were used to determine conservation status: (1) at Stage 1 (nonconserver) if the subject scored below 2.5 points on both Tasks 1 and 2, (2) at Stage 2 (transitional) if the subject scored at or above 2.5 points on either Task 1 or Task 2 , and (3) at Stage 3 (conserver) if the subject scored at or above 2.5 points on both tasks. Our results suggest an age trend in conservation status as follows: (1) The number of nonconservers dropped $100 \%$ from 5 to 7 years of age. (2) The number of conservers increased from $16 \%$ of the 5 -year-olds to $67 \%$ of the 7 -year-olds. (3) For the 6-year-olds, $22 \%$ were nonconservers, $52 \%$ were transitional, and $26 \%$ were conservers.

We found no evidence for the existence of sex differences in the attainment of conservation of number or continuous quantity. Chi-square analyses of the relationship between and conservation status and age also failed to reveal any sex differences on any of the tasks. These findings are consistent with the majority of investigations in which sex differences are reported (Elkind, 1967; Mogdil \& Mogdil, 1976).

Sporadic reports of sex differences in conservation performance that are found in the literature may possibly be attributed to chance, since they approach the order of 1 in 20 , the theoretical chance outcome. It is evident that more researchers need to report data on sex differences, significant or not.

Our one significant finding of a sex-ofexaminer effect reveals that the presence of a female examiner resulted in reliably higher scores for both sexes on Task 2. Further examination of the data showed that more of the male experimenters' subjects needed help with counting than did the female examiners' subjects, resulting in much lower scores.

The lack of any significant interaction effects, coupled with the data regarding examiner sex effects, is supportive of the methodology of Almy et al. (1966). This method fared well, and the data in this study are comparable to those in other published reports using this system (e.g., Brown, 1973). Conservation studies that incorporate standardized procedures need to be described in detail so that testing of the method as well as the 
theory can be conducted. Further, as methods are shown to be reliable, they should be used to reexamine and validate earlier research findings that have been criticized for lack of more rigorous experimentation.

\section{REFERENCES}

Almy, M., Chittenden, E., \& Miller, P. Young children's thinking. New York: Teachers College Press, 1966.

Braine RD, C. J. Piaget's theory of intelligence. Englewood Cliffs, N.J: Prentice-Hall, 1978.

Brekke, B., \& Williams, J. D. Conservation and sex. Perceptual and Motor Skills, 1973, 37, 14.

Brown, A. L. Conservation of number and continuous quantity in normal, bright, and retarded children. Child Development, 1973, 44, 376-379.

Elkind, D. Piaget's conservation problems. Child Development, $1967,38,15-27$.

Goldschmid, M. L. Different types of conservation and non- conservation and their relation to age, sex, IQ, MA, and vocabulary. Child Development, 1967, 38, 1229-1246.

Greenfield, P. M. On culture and conservation. In J. S. Bruner, R. R. Olver, \& P. M. Greenfield (Eds.), Studies in cognitive growth. New York: Wiley, 1966.

HunT, T. Early number "conservation" and experimenter expectancy. Child Development, 1975, 46, 984-987.

Lloyd, B. B. Studies of conservation with Yoruba children of differing ages and experiences. Child Development, 1971, 42 , 415-428.

Maccoвy, E. E., \& Jacklin, C. N. The psychology of sex differences. Stanford, Calif: Stanford University Press, 1974.

Mogdil, S., \& Mogdil, C. Piagetian research: Compilation and commentary. Atlantic Highlands, N.J: Humanities Press, 1976.

Wittig, M. A., \& Petersen, A. C. Sex-related differences in cognitive functioning: Developmental issues. New York: Academic Press, 1979.

(Received for publication January 16, 1982.) 